\title{
Surgery of Marfan's syndrome and related conditions of the aortic root (annulo-aortic ectasia)
}

\author{
DONALD N. ROSS, THOMAS G. FRAZIER, and \\ LORENZO GONZA LEZ - L A V I N ${ }^{1}$
}

\begin{abstract}
Departments of Surgery, Institute of Cardiology, National Heart Hospital, and Guy's Hospital, London
The surgical treatment of 14 patients with annulo-aortic ectasia and aortic valve regurgitation secondary to cystic medial necrosis is presented. Resection of the aneurysm and replacement with a tubular graft, and aortic valve replacement with a rigid prosthesis, are advocated for definitive treatment. Eighty-six per cent of the patients survive and are doing well six months to four and a half years after surgery.
\end{abstract}

As early as 1896, Marfan's syndrome had become a disease entity of interest to the clinician (Marfan, 1896) and, following the description of Erdheim in 1930 (Erdheim, 1930), it became important for the pathologist. Several reports followed relating cardiovascular pathology to Marfan's syndrome (Baer, Taussig, and Oppenheimer, 1943 ; Schorr, Braun, and Wildman, 1951; Sloper and Storey, 1953; Marvel and Genovese, 1951 ; Gore, 1952 ; McKusick, 1955 ; Macleod and Williams, 1956). It was not until 1956 and after the report of Bahnson and Nelson (1956), however, that this syndrome acquired surgical interest. Important advances in the field of cardiovascular surgery, and increasing understanding of the anatomy and physiopathology of this disease, have made possible the development of surgical therapy for patients with Marfan's syndrome and especially for those with annuloaortic ectasia.

The purpose of this presentation is to report our views and surgical experience in the surgical treatment of patients with this entity.

\section{CLINICAL MATERIAL}

Fourteen patients operated upon between October 1965 and July 1970 presented with annulo-aortic ectasia secondary to cystic medial necrosis and all had aortic valve regurgitation. Based on the criteria of skeletal (Fig. 1), ocular, and cardiovascular defects, it was possible to divide these cases into two definite groups - nine patients with Marfan's syndrome and five with the 'form fruste'. Twelve patients were males and two were females; their ages ranged from 11 to 59 with an average of 40 years.

All patients were or had been in left ventricular failure secondary to aortic regurgitation at the time

1Reprint requests to Lorenzo Gonzalez-Lavin, M.D., Institute of Cardiology. 35 Wimpole Street, London WIM $8 \mathrm{EX}$. of surgery. Two were operated upon on an emergency basis because of rapid deterioration. Eight patients gave a history of angina pectoris. Radiographic (Fig. پِ 2a) and electrocardiographic evidence of severe left ventricular enlargement and hypertrophy were present $\vec{\theta}$ in all patients. Twelve patients underwent angio-N graphic studies prior to surgery (Fig. 2b).

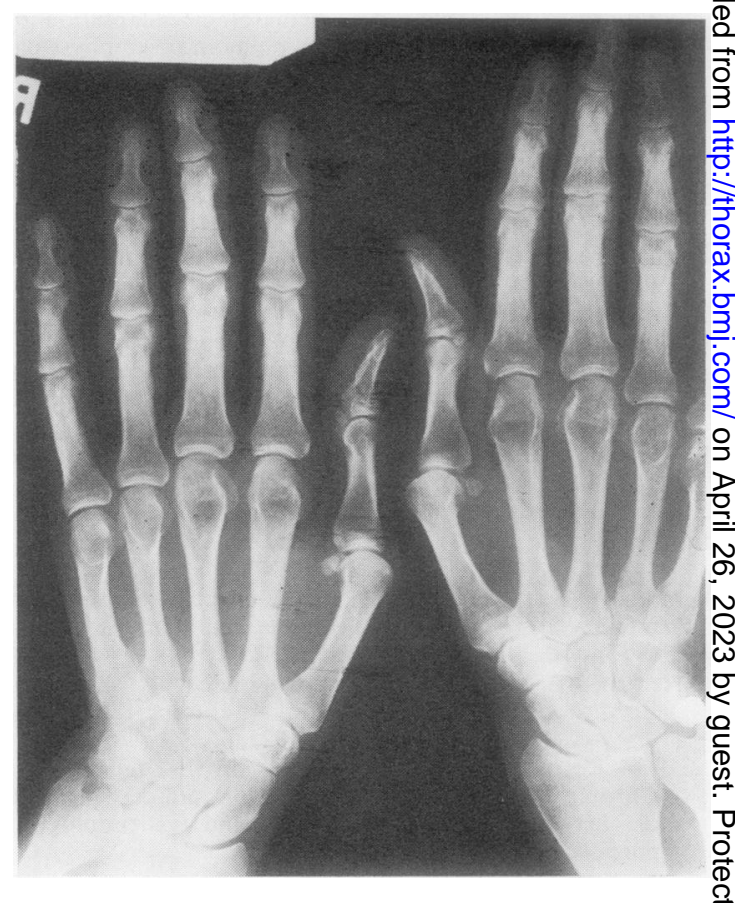

FIG. 1. Radiograph of the hands with a metacarpal indexत्ञ of 8.4 (Sutton, 1969): a characteristic finding in patient with Marfan's syndrome. 


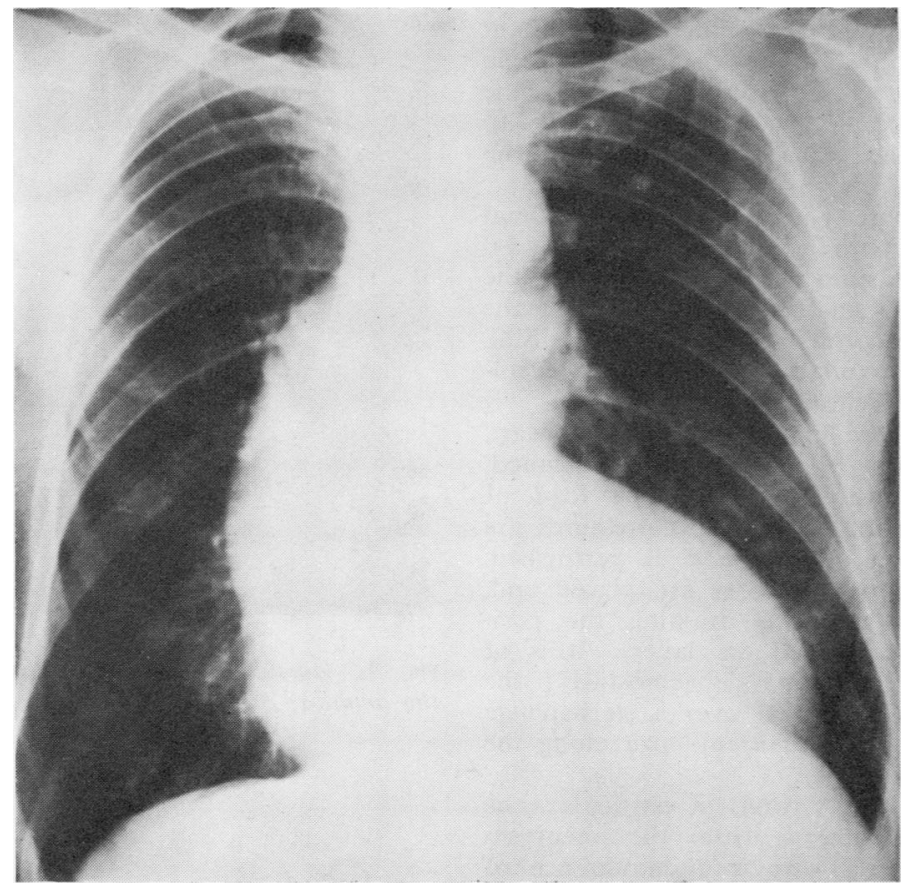

FIG. 2 (a). Postero-anterior chest radiograph with evidence of left ventricular enlargement and an ascending aortic aneurysm. (b) Retrograde aortogram outlining a large aneurysm of the annular level and severe aortic regurgitation.

\section{SURGICAL APPROACH}

Excellent exposure of the heart and ascending aorta is obtained through a midline sternotomy. The aneurysm usually occupies most of the anterior part of the pericardial cavity and the heart appears to be displaced towards the left (Fig. 3). The arterial line is placed in the aortic arch distal to the innominate artery ; for venous return to the pump a single line is placed in the right atrium. Normothermic high-flow cardiopulmonary bypass is established using a bubble oxygenator and haemodilution.

The ascending aorta is cross-clamped just proximal to the innominate artery, leaving enough cuff of aorta for the distal anastomosis. A vent is placed in the left ventricle and the aortic aneurysm is then incised longitudinally. A previously selected Dacron tubular graft is preclotted and the coronary lines are passed through the graft. Exposure of both coronary ostia is obtained and cannulation is performed after placing a pursestring suture to maintain the cannulae in place. The myocardium is perfused continuously throughout the procedure. Dissection of the aneurysm from the pulmonary artery and right and left atria is easily accomplished. It is then excised proximally to the aortic annulus and distally to $1 \mathrm{~cm}$ from the aortic clamp near the base of the innominate artery.

Attention is then directed to the aortic valve. It

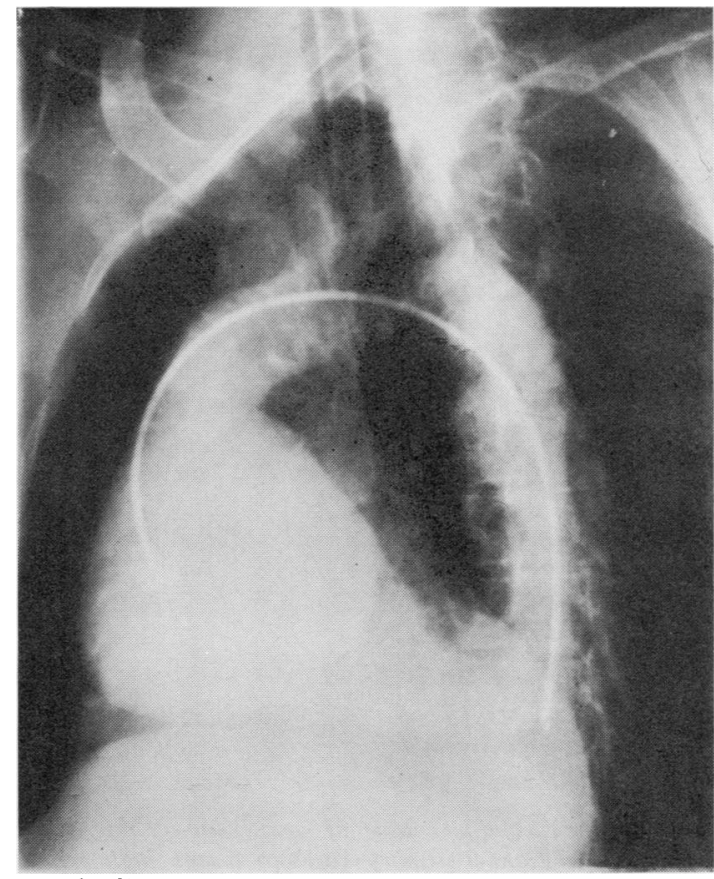

FIG. 2 (b). 
may be completely normal but rendered regurgitant due to dilatation of the annulus (Fig. 4). Multiple interrupted sutures are used for insertion of the prosthetic valve (Fig. 5), taking substantial bites with each stitch in both the valve sewing ring and the aortic annulus.

The Dacron tubular graft is tailored ; the proximal suture line is placed with a running suture of 3-0 Mersilene; the distal suture line is placed in the same manner, leaving a small opening to exclude the air after removing the coronary cannulae. The distal, and sometimes the proximal, suture lines are reinforced with a strip of Teflon felt.

After the air has been excluded from the heart, cardiopulmonary bypass is gradually discontinued, and the heart is allowed to resume the load of circulation. When systemic and venous pressures are adequate, decannulation of the heart is performed. Atrial and ventricular pacing wires are placed and, after securing haemostasis and draining the pericardium, the chest is closed in layers. It is of particular importance to achieve haemostasis; the use of topical thrombin applied over a steri-sponge is helpful in controlling a persistent ooze along the suture line.

Should a coronary artery, and, in particular, the right coronary artery, emerge from the aneurysm itself, the coronary ostia with a circumference of

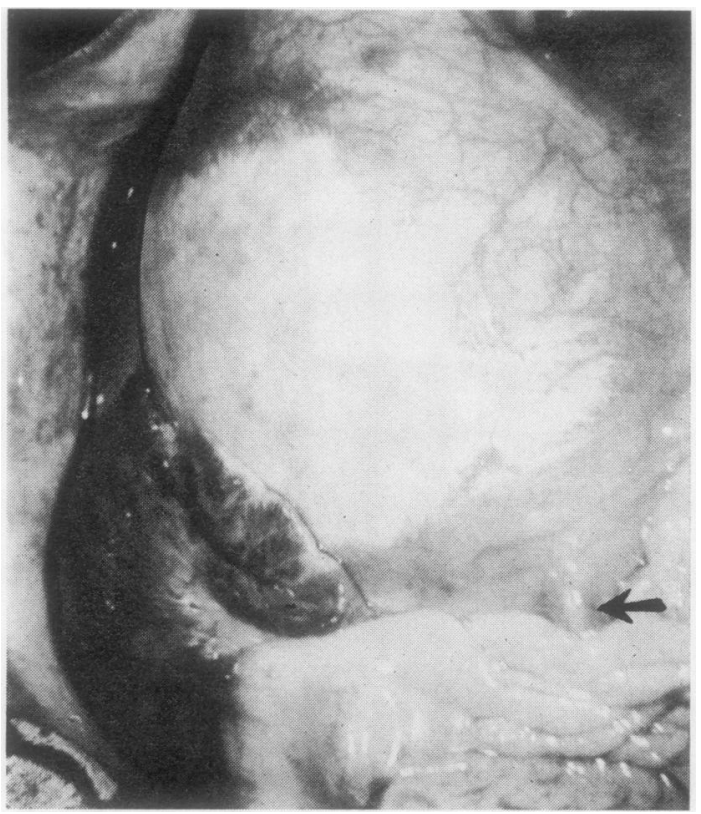

FIG. 3. Typical appearance of aneurysm of the aortic annulus. The right coronary (arrow) arises high within the aneurysm.

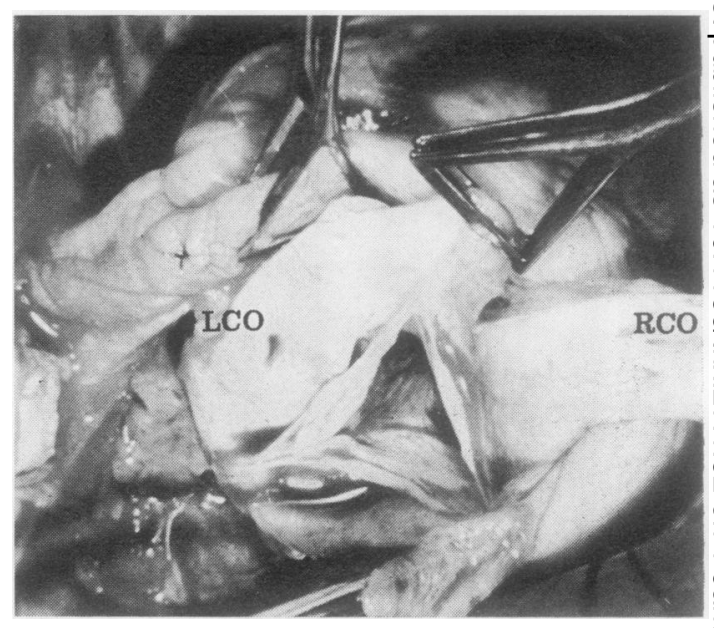

FIG. 4. Aortic valve regurgitation due to dilatation of the annulus. All three cusps appear normal.

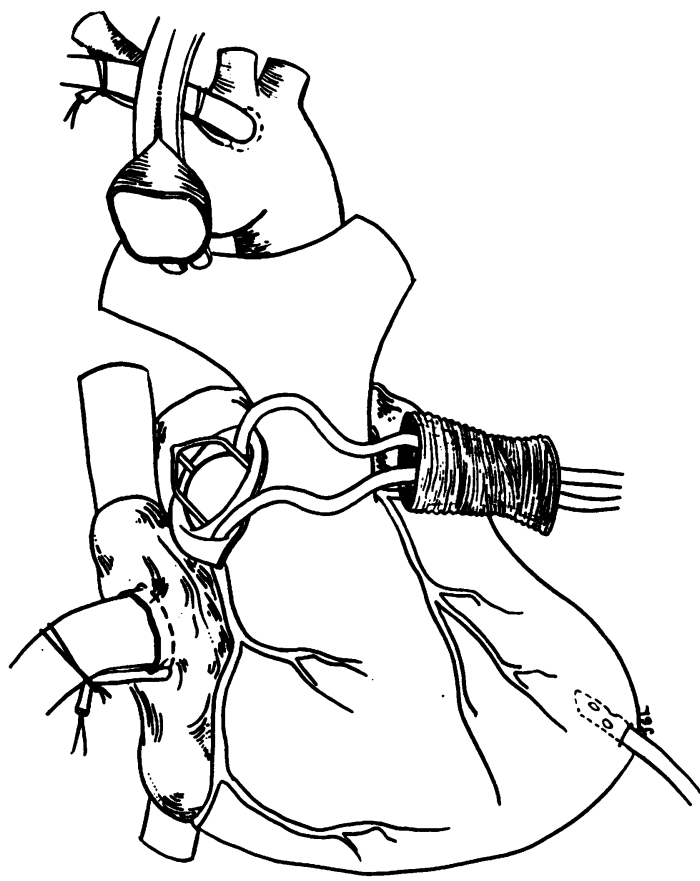

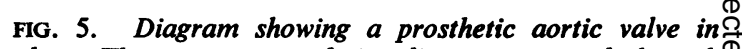
place. The coronary perfusion lines are passed through $\stackrel{\odot}{\Omega}$ the Dacron tubular graft, so coronary perfusion is continuous throughout the procedure. 
aortic wall is excised and reimplanted into the Dacron graft with a running suture of 4-0 Mersilene (Fig. 6). Wheat, Wilson, and Bartley (1964) have described an alternative: a tongue of aortic wall from the aortic annulus to the coronary ostia is preserved and a slit is then made in the prosthetic graft incorporating the tongue of aortic wall into the graft (Fig. 7).

\section{ANALYSIS OF SURGERY}

Thirteen patients had large fusiform ascending aortic aneurysms of the 'inverted' type; most of them had very thin walls. A double aortic lumen

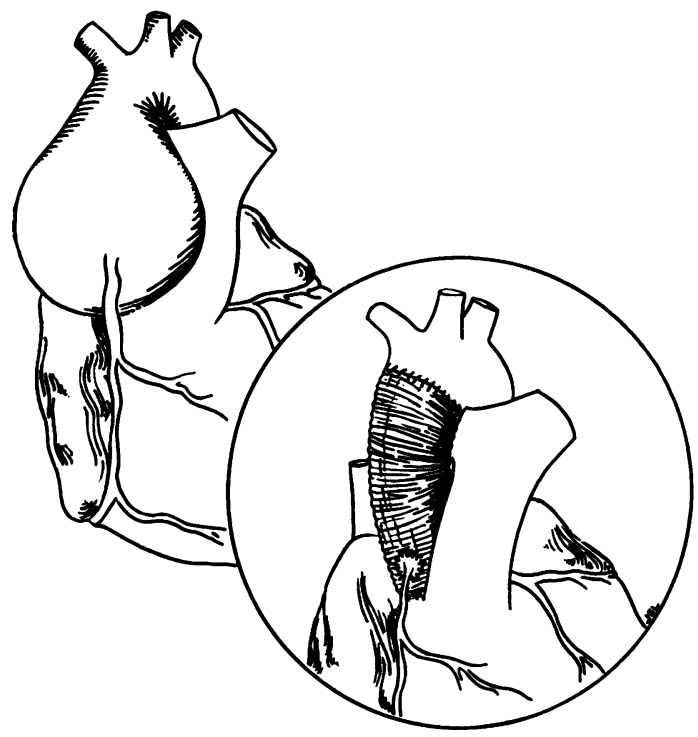

FIG. 6. When the right coronary emerges from the aneurysm itself, the coronary ostia with a small circumference of aortic wall is excised and re-implanted into the Dacron graft.

typical of chronic dissection was found in six patients (Fig. 8). In only one patient was the ascending aorta slightly dilated without dissection or aneurysm. All 14 patients had typical findings of cystic medial necrosis of the aortic wall (Fig. 9), even the patient without a large aneurysm. The aneurysms all tended to extend down to the aortic annulus.

Of the entire group, five patients had bicuspid valves. All the valves were attenuated. Histopathology was consistent with Marfan's syndrome

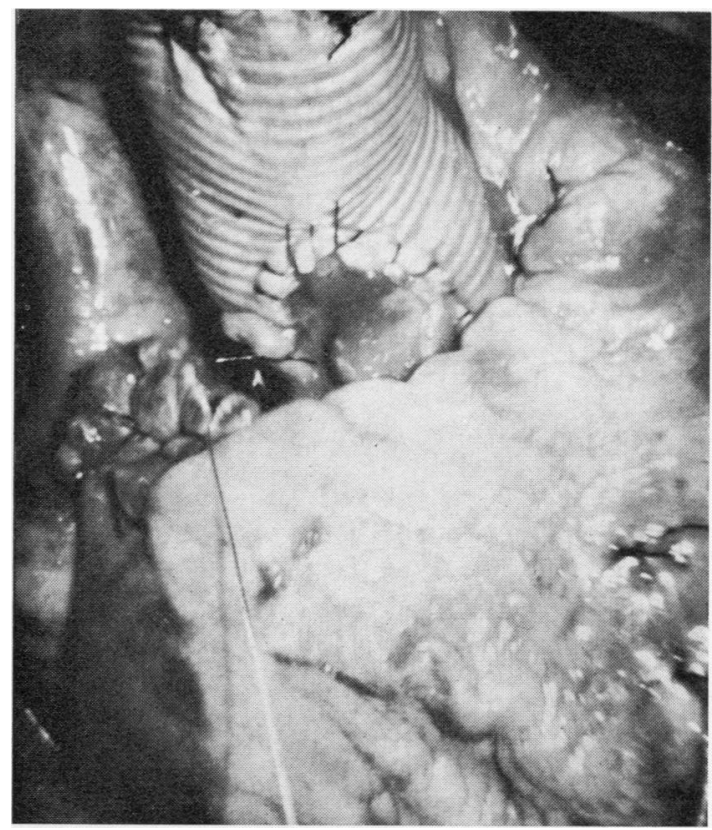

FIG. 7. In some cases a tongue of aortic wall from the aortic annulus to the coronary ostia is preserved and incorporated in the Dacron graft (Wheat et al., 1964).

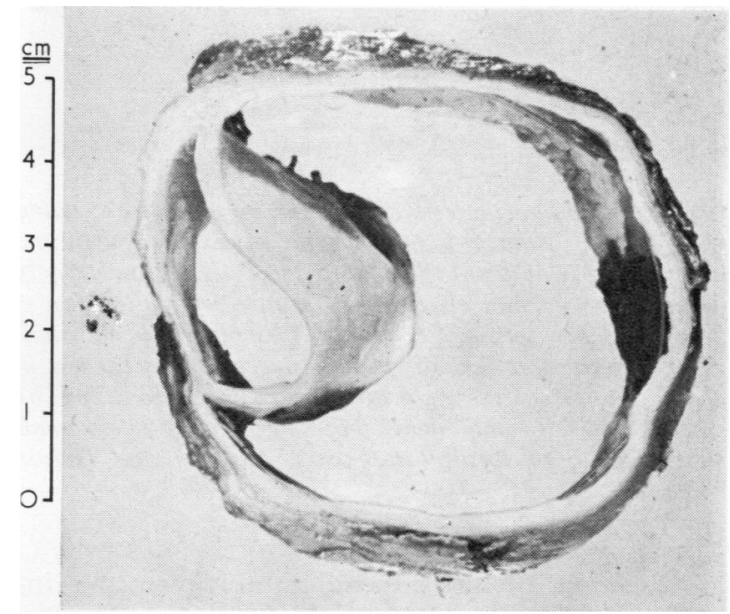

FIG. 8. Double aortic lumen, a typical finding of chronic dissection found at surgery in six of our patients.

in only three ; most of the valves were found to have a normal architecture. It was necessary to replace the valve in 13 instances. Starr-Edwards 
ball valves were inserted in 10 patients. A homograft was placed in one patient; it became regurgitant six months postoperatively and was subsequently replaced with a Starr-Edwards valve. Two patients underwent supported fascia lata aortic valve replacements. The other patient exhibited only minimal aortic regurgitation and the valve was left in place.

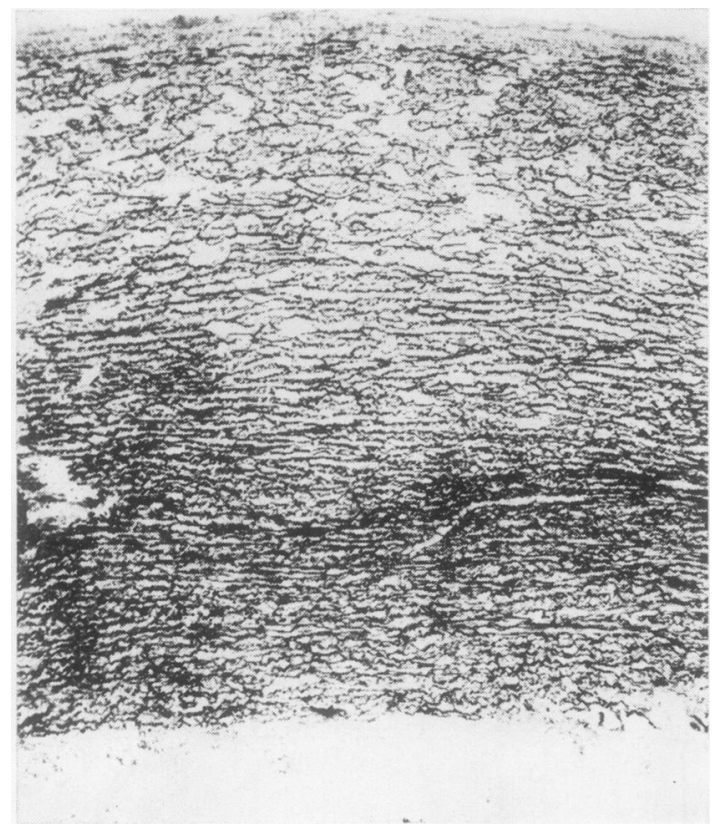

FIG. 9. A mild aortic lesion. Photomicrograph of ascending arch of aorta stained to show elastic tissue (black). Intima (above) shows minimal thickening only. Adventitia (largely absent) was normal elsewhere. Greater part of section is here formed by media. Elastica of its outer third is normal. As lumen is approached, progressively larger breaks in elastica appear; these lacunae proved to be filled by smooth muscle and acid mucopolysaccharide groundsubstance-both locally in excess. Verhoeff/van Gieson $\times 20$.

Resection of the ascending aorta to the innominate artery and replacement with a Dacron tubular graft was carried out in 10 instances, four of which were accompanied by right coronary artery re-implantation. In three patients a repair of the aorta was carried out with a Dacron patch after oversewing the double lumen of the aorta, and in one case, with only slight dilatation of the aorta, no resection was necessary.
RESULTS

Among the 14 patients there was one operative $\frac{\overline{ }}{\overline{0}}$ death, an operative mortality of $7 \%$. This oc- $\frac{\bar{\Phi}}{\Phi}$ curred in the first patient, who died with a 응 persistent ventricular fibrillation.

Only one late death occurred, 45 days after $\vec{\circ}$ surgery $(7 \%)$. This patient ran a persistently febrile course with arrhythmias to which he suc- $\vec{\omega}$ cumbed. Necropsy revealed a massive infarction $\stackrel{?}{\rightleftharpoons}$ of the right ventricle but no thrombosis of the $\vec{x}$ previously implanted right coronary artery. N

All the survivors are doing well six months to four and a half years after surgery. Only one in patient has evidence of aortic regurgitation-the $\mathrm{O}$ patient in whom the aortic valve was left in place at the time of surgery: it has not shown any in- $c$ crease in two and a half years.

\section{DISCUSSION}

Cystic medial necrosis is characterized by an ab- N normal increase of mucopolysaccharides in the tunica media of the arterial tree. This material $\sum^{\circ}$ accumulates and forms cystic areas which separate $\frac{\partial}{\partial}$ and compress the normal elastic fibres. The fibres become thinner and fragmentation frequently $\mathbb{Q}$ occurs with the end result of a weakened arterial $\overrightarrow{\vec{D}}$ wall. As the ascending aorta is the segment ex- $\frac{0}{3}$ posed to the distending forces of the left ventricular stroke and subjected to the highest pressure (Laplace Law), it is not surprising that it is the most common location of aneurysm in patients with cystic medial necrosis. These ఖ aneurysms are localized, as seen in 13 patients in $\dot{\sigma}$ this series, and therefore amenable to surgical 3 . resection. Only occasionally do they extend beyond the innominate artery (Bloodwell, Hallman, and Cooley, 1966). Excision and re-o placement with a tubular prosthetic graft is mandatory to avoid further distension of the arterialo wall.

Changes in the connective tissue usually result $\stackrel{\sigma}{\sigma}$ from the aortic annulus with separation of the N tunica media from the annulus fibrosus (Edwards. N Burchell, and Christensen, 1956). Weakness occurs $\sigma$ in this area and progressive dilatation may follow which renders even a normal aortic valve severely? regurgitant. The aortic valve may be completely normal or exhibit changes characteristic of this disease entity. Three valves in our series hado typical cystic degeneration. Bicuspid valves mayd be found in $20 \%$ of patients with cystic medial $\overrightarrow{\mathbb{D}}$ necrosis (Tung and Liebow, 1952), or perhaps in $\varrho$ even a higher incidence : five of our 14 patients 
had bicuspid valves $(35 \cdot 7 \%)$. When replacing the aortic valve, a rigid prosthesis is indicated to avoid further dilatation of the aortic annulus. In the present series, a homograft valve became regurgitant six months after surgery and was successfully replaced with a prosthesis. The homograft valve was well preserved but rendered regurgitant because of progressive annular dilatation. We doubt the wisdom of using autologous fascia lata because of the systemic alterations to connective tissue in this disease.

The right coronary artery, located slightly higher than the left in relation to the aortic annulus, is frequently involved in the aneurysmal process, as noted in four of our patients. This problem was approached by excision of the coronary ostia with a patch of aortic wall and free re-implantation into the prosthetic tubular graft. One of us has used the method of Wheat and colleagues in two cases, not included here, with excellent results.

In the light of our experience and that of others (Bloodwell et al., 1966; Muller, Dammann, and Warren, 1960 ; Ellis, Cooley, and De Bakey, 1961 ; Blanchard, Felder, Culligan, and MacLean, 1963 : Groves, Effler, Hawk, and Gulati, 1964 ; Chapman et al., 1965 ; Merendino, Winterscheid, and Dillard, 1967), the surgical treatment of patients with annulo-aortic ectasia and aortic regurgitation secondary to cystic medial necrosis should consist of resection of the aneurysm and replacement with a tubular prosthetic graft, and aortic valve replacement with a rigid prosthesis. The technique of free implantation of the right coronary artery into the prosthetic graft is recommended when this artery arises from the aneurysm. This surgical approach has given us good results; $85.7 \%$ of the patients in this series of 14 survive, and are doing well, six months to four and a half years after surgery.

We are grateful to Dr. G. A. K. Missen, Department of Pathology, Guy's Hospital, London, for selecting and preparing the photomicrograph in Fig. 9, and to Miss Julie Brunner, S.R.N. for the diagrams used.

\section{REFERENCES}

Baer, R. W., Taussig, H. B., and Oppenheimer, E. H. (1943). Congenital aneurysmal dilatation of the aorta associated with arachnodactyly. Bull. Johns Hopk. Hosp., 72, 309.

Bahnson, H. T., and Nelson, A. R. (1956). Cystic medial necrosis as a cause of localized aortic aneurysms amenable to surgical treatment. Ann. Surg., 144, 519.
Blanchard, R. J. W., Felder, D. A., Culligan, J. A., and MacLean, L. D. (1963). Cardiovascular surgery in Marfan's syndrome. Ann. Surg., 158, 990.

Bloodwell, R. D., Hallman, G. L., and Cooley, D. A. (1966). Aneurysm of the ascending aorta with aortic valvular insufficiency. Arch. Surg., 92, 588.

Chapman, D. W., Beazley, H. L., Peterson, P. K., Webb, J. A., and Cooley, D. A. (1965). Annulo-aortic ectasia with cystic medial necrosis. Diagnosis and surgical treatment. Amer. J. Cardiol., 16, 679.

Edwards, J. E., Burchell, H. B., and Christensen, N. A. (1956). Specimen exhibiting the essential lesion in aneurysm of the aortic sinus. Proc. Mayo Clin., 31, 407.

Ellis, P. R., Cooley, D. A., and De Bakey, M. E. (1961). Clinical considerations and surgical treatment of annulo-aortic ectasia. J. thorac. cardiovasc. Surg., 42, 363.

Erdheim, J. (1930). Medionecrosis aortae idiopathica cystica. Virchows Arch. f. path. Anat., 276, 187.

Gore, I. (1952). Pathogenesis of dissecting aneurysm of the aorta. Arch. Path., 53, 142.

Groves, L. K., Effler, D. B., Hawk, W. A., and Gulati, K. (1964). Aortic insufficiency secondary to aneurysmal changes in the ascending aorta: Surgical management. J. thorac. cardiovasc. Surg., 48, 362.

Macleod, M., and Williams, A. W. (1956). The cardiovascular lesions in Marfan's syndrome Arch. Path., 61, 143.

McKusick, V. A. (1955). The cardiovascular aspects of Marfan's syndrome: A heritable disorder of connective tissue. Circulation, 11, 321.

Marfan, A. B. (1896). Un cas de déformation congénitale des quatre membres, plus prononcée aux extrémites, charactérisée par l'allongement des os avec un certain degré d'amincissement. Bull. Soc. Méd. Hôp. Paris, 3 e sér., 13, 220.

Marvel, R. J., and Genovese, P. D. (1951). Cardiovascular disease in Marfan's syndrome. Amer. Heart J., 42, 814.

Merendino, K. A., Winterscheid, L. C., and Dillard, D. H. (1967). Cystic medial necrosis with and without Marfan's syndrome. Surgical experience with 20 patients and a note about the modified bicuspidization operation. Surg. Clin. N. Amer., 47, 1403.

Muller, W. H., Jr., Dammann, J. F., Jr., and Warren, W. D. (1960). Surgical correction of cardiovascular deformities in Marfan's syndrome. Ann. Surg., 152, 506.

Schorr, S., Braun, K., and Wildman, J. (1951). Congenital aneurysmal dilatation of the ascending aorta associated with arachnodactyly: an angiographic study. Amer. Heart J., 42, 610.

Sloper, J. C., and Storey, G. (1953). Aneurysms of the ascending aorta due to medial degeneration associated with arachnodactyly (Marfan's disease). J. clin. Path., 6, 299.

Sutton, D. (ed.) (1969). A Textbook of Radiology. Livingstone: Edinburgh.

Tung, H. L., and Liebow, A. A. (1952). Marfan's syndrome: Observations at necropsy: with special reference to medionecrosis of the great vessels. Lab. Invest., 1, 382.

Wheat, M. W., Jr., Wilson, J. R., and Bartley, T. D. (1964). Successful replacement of the entire ascending aorta and aortic valve. J. Amer. med. Ass., 188, 717. 